\title{
Aplicação de um método ergonômico para avaliação da permanência e atratividade em espaço público aberto: estudo de caso Parque Vitória Régia, Bauru - SP
}

ALVES, Silvana A. ${ }^{1}$

SOUZA, Léa C. L.

FARIA, João R. G.

\author{
${ }^{1}$ Universidade Estadual Paulista, Bauru, Brasil. silvana@faac.unesp.br
}

\begin{abstract}
Resumo
Diversas são as pesquisas sobre avaliação do espaço público urbano, porém nem todas estabelecem uma relação entre a configuração dos espaços com o ambiente térmico, a ergonomia ambiental e o comportamento dos usuários. Para compreender essa relação, o objetivo desse trabalho é apresentar o modelo DePAN (Design para a Permanência e Atratividade em Nichos de espaços abertos de convívio), fundamentado em malhas gráficas, criado para avaliar a influência do design e da ergonomia dos espaços públicos abertos no conforto térmico e nos modos como os usuários se apropriam do espaço. Sua aplicabilidade é comprovada através de um estudo de caso realizado em um parque na cidade de Bauru-SP. Para realizar tal avaliação foram escoIhidos os nichos desse espaço público, formados por elementos morfológicos e mobiliários urbanos e definidos pelos seus arranjos espaciais. Os dados coletados foram transferidos para um Sistema de Informação Geográfica (SIG), o que possibilitou efetuar a sobreposição das malhas em camadas. Os resultados indicam que o modelo DePAN permite verificar as características espaciais, ergonômicas e a qualidade térmica gerada pelo design dos espaços, bem como avaliar a interferência desses aspectos na forma de usabilidade do espaço. O modelo permite gerar uma classificação para cada nicho e definir um valor para o nível de serviço oferecido.
\end{abstract}

Palavras-Chave: espaço público aberto, ambiente térmico, malhas gráficas, Sistema de Informação Geográfica.

\begin{abstract}
There are several researches on evaluation of urban public space, but not all establish a relationship between the configuration of spaces with the thermal environment, ergonomics and environmental behavior of users. To understand this relationship, the aim of this paper is to present the model DEPAN (Design for Permanence and Attractiveness in niches open spaces of conviviality), based on graphical meshes, which were designed to evaluate the influence of design and ergonomics of open public spaces in the human thermal comfort and the ways in which users appropriate the space. Its applicability is demonstrated through a case study conducted in a park in the city of Bauru-SP. To perform this evaluation public space niches were chosen. They were formed by morphological elements and street furniture and defined by their spatial arrangements. The collected data were incorporated into a Geographic Information System (GIS), which allowed the overlay of meshes. The results indicate that the DEPAN model allows the verification of the spatial characteristics, thermal quality and ergonomic design generated by spaces, as well as the evaluation of the influence of these aspects in the way of using the spaces. The model allows the generation of a classification for every niche and set a value for the level of service offered.
\end{abstract}

Keywords: urban public space, thermal environment, graphical mesh, Geographical Information System 


\section{Introdução}

A qualidade dos espaços públicos abertos é condicionada pelas suas características de design, ergonômicas e condições microclimáticas oferecidas. Neste sentido, os espaços públicos abertos apresentam uma diversidade de aspectos espacial e temporal, que influenciam na atratividade e permanência dos indivíduos nestes ambientes. Uma forma de analisar essa relação é através da ergonomia, que engloba a análise dos aspectos arquiteturais e térmicos que interferem positiva ou negativamente na apreensão do espaço pelas pessoas e, consequentemente, na sua usabilidade. A ergonomia avalia a interação entre ambiente construído e comportamento humano, considerando a análise da relação entre as condições físico/arquiteturais, os aspectos microclimáticos e a sensação térmica dos usuários do espaço, que irão afetar os fatores físicos, fisiológicos e cognitivos do indivíduo.

A forte relação entre as condições microclimáticas, a sensação térmica dos indivíduos e seu comportamento é apontada por Bruse (2007) como fatores de grande relevância em estudos sobre o impacto dos ambientes térmicos nas cidades e na vida de seus cidadãos. Estudos sobre o impacto da sensação térmica sobre o comportamento, as expectativas e os desejos dos pedestres são recomendados pelo autor para subsidiar projetos urbanos.

A necessidade de conceber espaços abertos em consideração às condições climáticas é destacada também por Katzschner (2003) que relata a experiência realizada na Dinamarca nos últimos anos, onde onde os hábitos cotidianos incorporaram a vida ao ar livre em uma quantidade de meses ao longo do ano maior do que ocorria nas décadas passadas. Esse fato levou à necessidade de serem definidos métodos para avaliar as condições de conforto térmico em conexão com o comportamento das pessoas, a forma como o espaço é utilizado e sua relação com o design urbano. Para tanto o autor propõe uma metodologia desenvolvida por mapeamento, a qual centra-se na análise espacial de zonas de conforto térmico, considerando como principais questões para análise: a morfologia do sítio, os dados climáticos e os dados de tempo (períodos de tempo de coleta e observação). Estes dados foram aplicados em uma grelha espacial prédefinida, a qual relaciona os dados coletados em campo com os resultados de entrevistas e, assim, demonstra que há uma estreita ligação entre comportamento humano, estruturas morfológicas e conforto térmico.
Nikolopoulou e Steemers (2003) ressaltam que, na avaliação do espaço público aberto, a adaptação do indivíduo ao lugar é um fator importante e que interfere na usabilidade do espaço. Consideram que a adaptação pode ser separada em três categorias: física, fisiológica e psicológica, sendo a última uma reação humana que não tem relação direta com a resposta humana a um estímulo físico, mas depende da informação que cada indivíduo tem para uma situação particular.

$\mathrm{Na}$ busca de uma ferramenta para avaliar o espaço público aberto que concilie a relação entre o design do espaço, as características ergonômicas e $\mathrm{o}$ ambiente térmico com $\mathrm{o}$ comportamento humano e a usabilidade do espaço, foi criado o modelo DePAN - Design para a Permanência e Atratividade em Nichos de espaços abertos de convívio (ALVES, 2012). Trata-se de uma ferramenta baseada na construção e aplicação de malhas gráficas, que considera que os elementos construtivos e naturais podem ser representados graficamente, de modo a indicar os atributos existentes no espaço e facilitar na avaliação de sua influência para a atratividade e permanência das pessoas. O Modelo DePAN analisa o espaço por nichos, que são os espaços formados por elementos morfológicos e mobiliários urbanos, dando uma conformação para o espaço e formando arranjos espaciais que podem ser distintos e de tamanhos variados. Os fatores que exercem essa atração e geram a permanência são considerados os atributos do nicho.

O modelo DePAN foi inspirado no método MEGA criado por Bins Ely (1997), que consiste em malhas gráficas produzidas para avaliar os atributos físicos e ambientais de abrigos de ônibus, relacionados com o comportamento dos usuários. No entanto, o modelo DePAN é uma expansão para aplicação nos espaços públicos abertos, tais como: praças, bosques e parques urbanos. Neste artigo é apresentada a aplicação do modelo DePAN em um parque urbano localizado na cidade de Bauru-SP.

\section{Objetivo}

O objetivo deste artigo é apresentar e aplicar um método de avaliação da permanência e atratividade de usuários de espaços públicos abertos, denominado modelo DePAN - Design para a Permanência e Atratividade em Nichos de espaços abertos de convívio, coleta de dados e registro nas malhas gráficas 


\section{Método}

O modelo DePAN é fundamentado em malhas gráficas, que são sobrepostas e a partir das quais é atribuída uma classificação aos espaços avaliados em função dos atributos oferecidos, determinando-se um nível de serviço para os mesmos. Assim, os procedimentos metodológicos adotados são: seleção de uma área de estudo, desenvolvimento e definição de tipos de malhas gráficas DePAN, registro de dados coletados, tratamento dos dados em um SIG (Sistema de Informações Geográficas), avaliação da área pelo método DePAN e definição do nível de serviço, validação do modelo.

\section{1. Área de Estudo}

Como área de estudo foi escolhido um parque urbano localizado na cidade de Bauru- SP. O parque possui área de $42.810 \mathrm{~m} 2$, na qual $90 \%$ equivale ao solo permeável e os $10 \%$ restantes se referem à área pavimentada. $O$ parque apresenta uma configuração espacial que produz vários subespaços, devido à sua extensão, ao seu design e às suas características topográficas, com declividade suave em torno de $6 \%$ em algumas partes e bastante acentuada em outras, gerando taludes e desníveis de até $21 \%$. São identificados os seguintes subespaços: playground, anfiteatro aberto, área de bancos, sanitários, e diversos subespaços gramados, planos ou inclinados, e boa parte deles é arborizado, o que gera espaços de sombra e contribui para determinar o microclima local. Estes subespaços receberam uma identificação por números (do $\mathrm{n}^{\circ} 2$ ao $\mathrm{n}^{\circ} 22$ conforme pode ser visto na Figura 1. Há, ainda, os caminhos para circulação de pedestres, permeando o parque e o lago artificial.

Figura 1: Identificação dos subespaços do Parque Vitória Régia

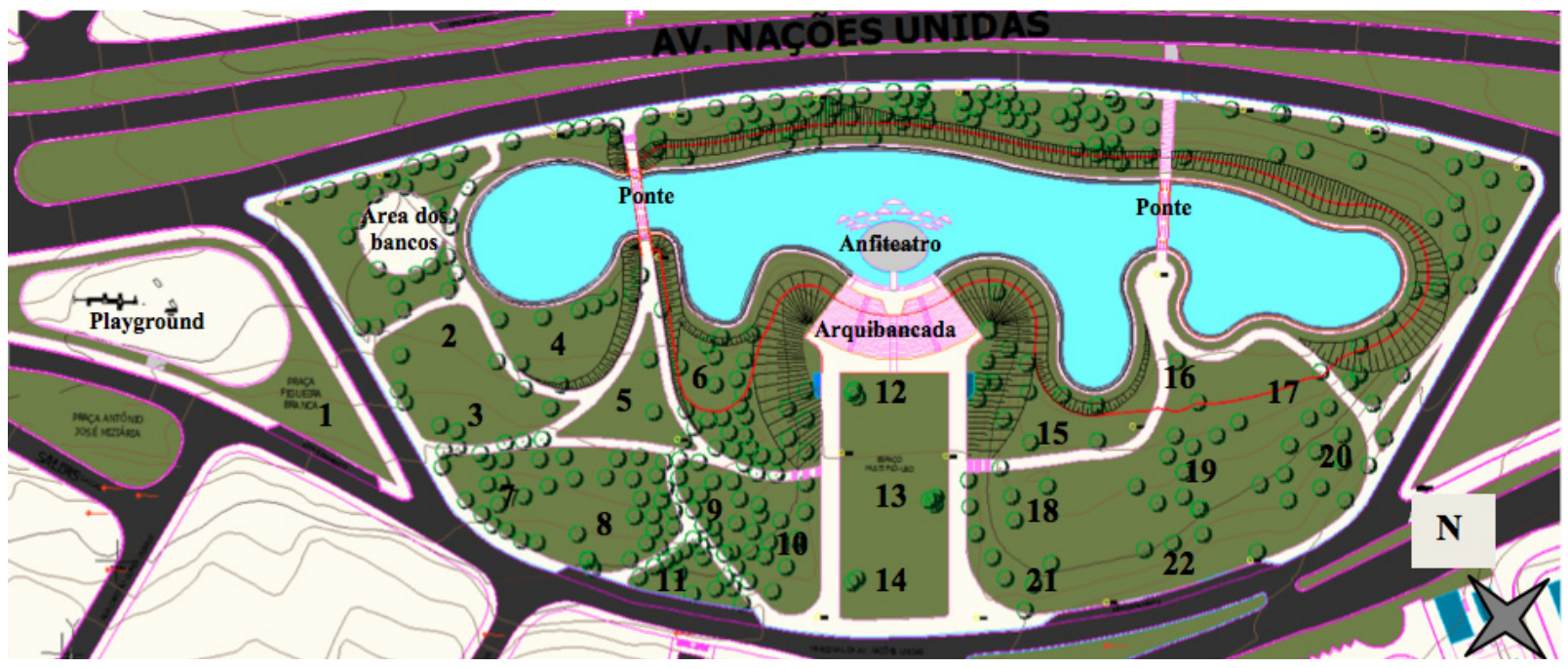

\subsection{Desenvolvimento e definição dos ti- pos de malhas gráficas}

As malhas gráficas são o produto gerado por este método e cada atributo de um espaço gera uma malha. Assim, a quantidade de malhas está condicionada a quantidade de atributos estudados. As malhas gráficas foram confeccionadas conforme os conceitos da psicologia ambiental que sugere uma distância mínima necessária entre as pessoas. Essa distância é denominada de espaço pessoal definida como uma área circundante ao corpo do indivíduo SOMMER (1973). A distância pessoal é dividida por Hall (1977) em: fase próxima e fase afastada. Nesta pesquisa, por se tratar de espaço público urbano, foi adotada a fase afastada, na qual as pessoas garantem uma distância de 0,80 m a 1,20 m, umas das outras.
Para determinar as dimensões das células das malhas gráficas, foi considerado também os dados antropométricos do corpo humano. Neste caso, foi adotada como medida para o corpo a largura dos ombros indicada por Panero e Zelnik (1989), cuja distância horizontal, para percentil 95 , é de $36,8 \mathrm{~cm}$ de profundidade e $65,5 \mathrm{~cm}$ de largura (Figura 2).

Figura 2: Dimensões antropométricas do corpo humano. Fonte: Sulliman Gato Scriboni (2011) adaptado de Panero e Zelnik (1989).

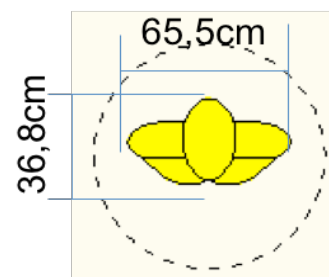


Com base nos parâmetros citados foi escolhida a forma quadrada para a construção da malha, com células de dimensão de 1,20 m x 1,20 m. Essas medidas foram adotadas para que um indivíduo adulto caiba dentro de uma célula e o "espaço pessoal" seja garantido. Segundo Hall (1977) a distância íntima na fase próxima é de até $0,15 \mathrm{~m}$ e na fase afastada é variável entre $0,15 \mathrm{~m}$ a $0,45 \mathrm{~m}$. Portanto, em caso de pessoas íntimas, a célula pode ser ocupada por dois indivíduos adultos ou uma pessoa adulta e mais duas crianças, de acordo com as dimensões antropométricas infantis apresentadas por Silva, Franco e Spinosa (2008b).

As malhas gráficas são sobrepostas a planta baixa do espaço público que se pretende avaliar. Assim, faz-se uma identificação e delimitação dos subespaços e dos seus nichos. Essa identificação é feita de acordo com a espacialização dos mobiliários urbanos ou elementos morfológicos que definem uma característica para o subespaço e para os nichos que ele abrange. Dentro de um mesmo subespaço podem haver vários nichos, que são identificados pelos arranjos espaciais dos mobiliários urbanos, como os bancos, por exemplo. A figura 3 representa um subespaço que foi identificado pelo arranjo circular dos bancos, e devido ao afastamento que existe entre cada um deles foi determinado que cada banco forma um nicho. A partir da identificação do nicho, as células são numeradas como mostra a Figura 3.

Figura 3: Delimitação e identificação dos nichos existentes em uma área do espaço público aberto, destacados pela cor amarela e com definição da quantidade de células de cada um

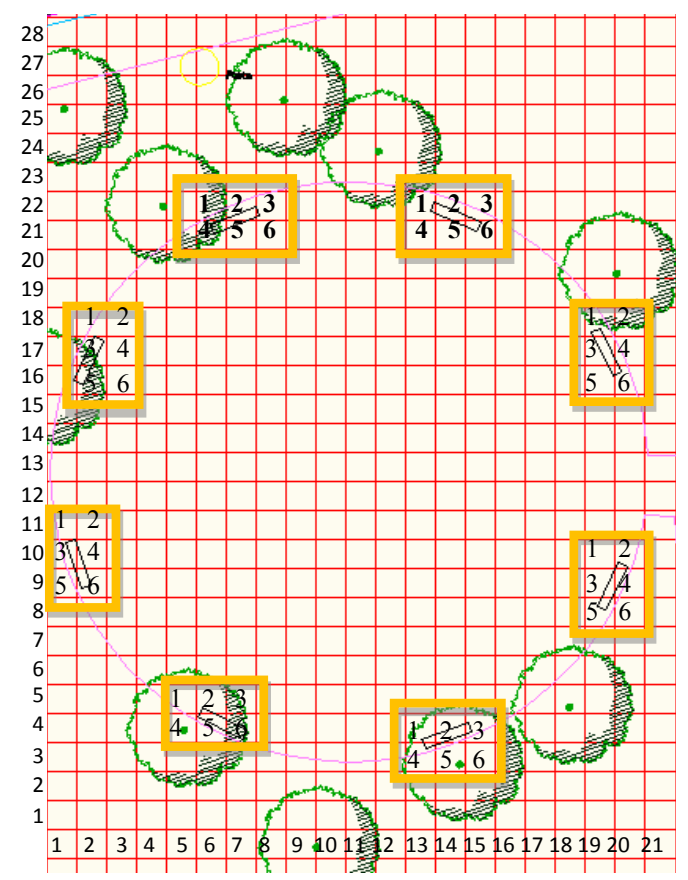

Os nichos variam de tamanho, conforme o tipo de arranjo espacial formado por seus mobiliários urbanos (bancos ou outros elementos, desde que utilizados pelos usuários para sentar, como muretas, escadas, entre outros). O tamanho do nicho é variável, assim como a quantidade de células do nicho.

\subsubsection{Tipos e classes das malhas gráficas}

Para cada atributo estudado foi criada uma malha gráfica que recebeu uma denominação relacionada ao tipo de atributo. Foram selecionados os aspectos considerados os atributos que geralmente são encontrados nas praças e parques urbanos e contribuem para a formação do design, da ergonomia e do ambiente térmico.

Para avaliar o grau de influência de cada um dos atributos na usabilidade desses ambientes, foram criadas nove malhas, em cinco delas são anotados os registros dos atributos que configuram o espaço e definem as suas características físico-funcionais, portanto de caráter fixo. Nas outras quatro malhas são feitos os registros dos aspectos ambientais, por meio de medições térmicas (temperatura e umidade do ar, temperatura superficial, e velocidade do vento) e do comportamento das pessoas, portanto, de caráter dinâmico e temporal.

Assim, foram estabelecidas duas classes de malhas, as malhas fixas e as malhas dinâmicas. As malhas fixas são: Malha Banco, Malha Encosto de Banco, Malha Arranjo Espacial dos Bancos, Malha Material do Banco e Malha Revestimento de Piso. Para essas faz-se uma observação única, sempre no início do levantamento, pois são os atributos fixos. As malhas dinâmicas são: Malha Sol/Sombra, Malha Temperatura Superficial, Malha Pessoas e Malha Interação entre Pessoas. Essas são trocadas a cada quinze minutos, pois representam os atributos que variam ao longo do tempo. O desenvolvimento das malhas pessoas e interação entre pessoas é destinado especificamente à validação do método DePAN, enquanto as demais são integrantes do método.

\subsection{Registro dos dados coletados nas malhas gráficas}

Os dados observados em campo são registrados nas células das malhas gráficas e normalizados, variando de 0 (zero) a 1 (um), sendo 0 para a menor atratividade do atributo e 1 para a maior atratividade do atributo. A única exceção é a 
malha de interação entre pessoas, que é preenchida apenas por símbolos e só é utilizada para a validação do modelo.

Nas malhas Banco e Encosto de Banco é inserido na célula o número 1 (um) nos locais onde há a presença desse mobiliário, onde não há, preenche-se com o número 0 (zero). No caso da malha Arranjo Espacial dos Bancos foram estabelecidas três formas de arranjo: banco isolado, arranjo sócio-fugal (indica bancos dispostos de modo que dificulta a socialização das pessoas) e arranjo sócio-petal (indica bancos dispostos de modo que facilita a socialização das pessoas). Assim, o arranjo isolado corresponde a 0 (zero), o sócio-fugal a 0,5 (meio) e o sócio-petal a 1 (um).

As malhas Material do Banco e Revestimento de Piso são preenchidas por valores de atratividade baseados na difusividade térmica do material, calculada a partir de valores de condutividade térmica, calor específico e média da densidade de massa aparente da NBR 15220:2005. Os materiais com maior difusividade assumiram valor 0 (metal, por exemplo), enquanto os materiais de menor difusividade assumiram valor 1 (madeira). O mesmo critério foi adotado para especificar os valores da malha revestimento de piso e neste caso foi aplicado o maior valor de atributo para o revestimento em grama.

A malha Sol/Sombra apresenta um diferencial no preenchimento, de forma que no verão privilegia-se a sombra e no inverno, o sol. Assim, em dias quentes preenche-se as células com sombra com o número 1 (um) e com sol com 0 (zero), no inverno o contrário. O 0,5 (meio) indica sombra rala nas duas estações.

A malha Temperatura Superficial representa as temperaturas medidas nas superfícies dos bancos e revestimentos de piso, após serem normalizadas por faixas de temperaturas. Primeiramente foi definida a faixa de temperatura de conforto com base em Lamberts e Xavier (2002), que indicam a temperatura de $250 \mathrm{C}$ como sendo a temperatura de conforto das superfícies para pessoas calçadas em atividades sedentárias. A partir dessa temperatura de referência de conforto, adotou-se uma tolerância de $\pm 10 C$, estabelecendo-se uma faixa de conforto de 240C a 25,9oC. Essa faixa corresponde ao valor 1(um). Com faixas com intervalos de 5oC, foram atribuídos valores de distanciamento do conforto, assim, a faixa de $260 \mathrm{C}$ a $30,90 \mathrm{C}$, por exemplo, corresponde a 0,8 .

Para a malha Pessoas é inserido o número 1 (um) onde há presença de indivíduos na célula e quando não há, se preenche o 0 (zero). Para a malha Interação entre Pessoas o preenchido é feito pelo símbolo universal que representa gênero. A faixa etária foi indicada por cor e a interação entre as pessoas por um traço reto ou um traço em forma de arco unindo-as.

\subsection{Tratamento dos dados obtidos com as malhas gráficas em um SIG}

A malha gráfica é formada por um conjunto de células, representadas pelas coordenadas " $X$ " e "Y". Cada atributo que compõe uma malha específica representou os valores do eixo " $Z$ " da célula. Após o preenchimento das células das nove malhas, os dados foram transportados para um ambiente de Sistema de Informações Geográficas (SIG). Foi utilizado o ArcGIS versão 10, da ESRI, instalado no laboratório de Conforto Ambiental e Eficiência Energética da Universidade Federal de São Carlos (UFSCar).

O SIG permitiu o mapeamento da malha somatória DePAN. Para isso, foram feitas interpolações dos pesos de cada célula (Figura 4). Através do SIG foi possível considerar o valor da célula como coordenada $Z$ e confeccionar um mapa 3D para cada nicho (Figura 5). O mapa resultante possibilitou a análise visual dos nichos de permanência e atratividade.

A aplicação das malhas gráficas foi feita no período da manhã e da tarde, em um dia para cada estação do ano. Os mapas produzidos no ArcGIS10 representam esses períodos, com a graduação de cores das células, permitindo identificar os índices mais elevados de atributos, em comparação com as células que oferecem um índice mais baixo de atributos, indicados nas legendas das figuras 4 e 5 .

O modelo DePAN considerou pesos iguais para todas as malhas, assim o valor ergonômicoambiental de cada célula é a soma dos valores dos atributos, gerando um valor resultante para cada célula da malha somatória. Os valores das células determinam o índice DePAN e identificam o nível de serviço do nicho.

\subsection{Avaliação da área pelo método DePAN e definição do nível de serviço}

A avaliação da área pelo Método DePAN é feita pelo calculado do desvio padrão encontrado entre os valores das células da malha somatória. Quanto menor o desvio padrão, maior a homogeneidade do nível de serviço do nicho. $\mathrm{O}$ nível de serviço mais baixo corresponde a 
Figura 4: Interpolação dos valores dos pontos no ArcGIS 10 para um dos subespaços no período da manhã

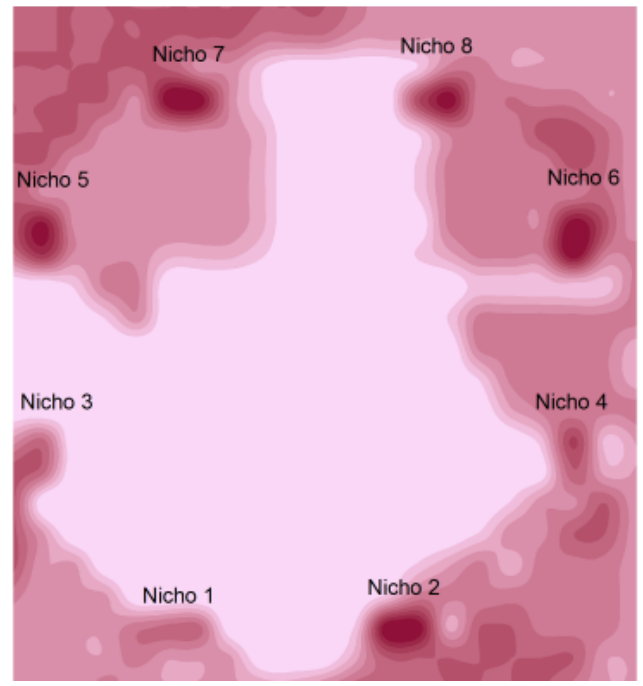

\section{LEGENDA}

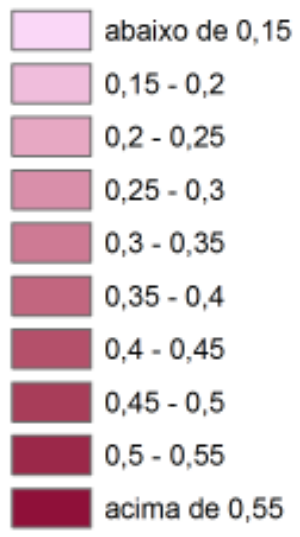

Figura 5: Representação em 3D dos valores DePAN, para oito nichos existentes em um subespaço, período da manhã.

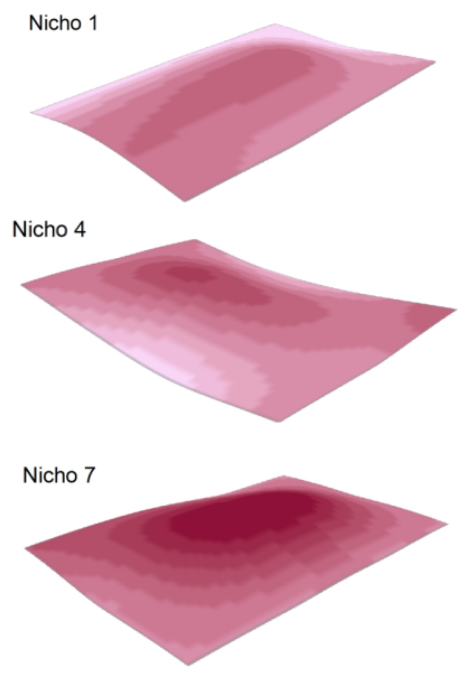

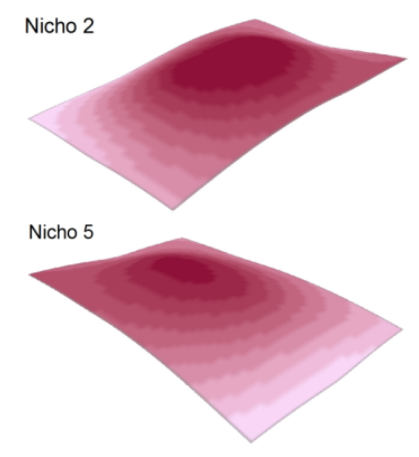

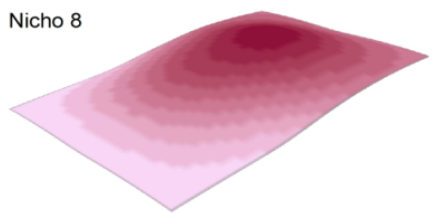

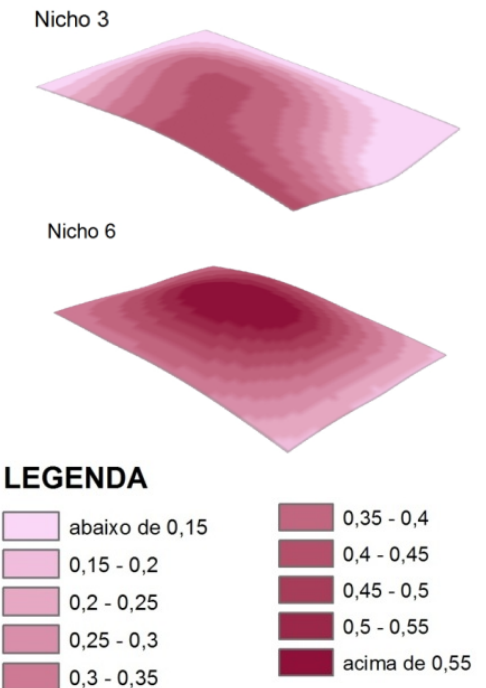

Tabela 1: Níveis de serviço correspondente aos índices DePAN

\begin{tabular}{|c|c|c|c|c|c|}
\hline Classes DePAN & A & B & C & D & E \\
\hline Nível de serviço DePAN & Excelente & Muito bom & Bom & Pouco satisfatório & Insatisfatório \\
\hline Faixa dos índices DePAN & Acima de 0,45 & Entre 0,35 e 0,45 & Entre 0,25 e 0,35 & Entre 0,15 e 0,25 & Abaixo de 0,15 \\
\hline
\end{tabular}

valores próximos a 0 (zero) e desvio padrão elevado, enquanto o nível de serviço mais alto corresponde a valores próximos a 1 (um) e desvio padrão baixo. Conforme a média e 0 desvio, os níveis de serviço dos nichos foram classificados de A a E (Tabela 1).

Em todos os dias avaliados foram verificadas as condições mais desfavoráveis, tanto para a parte da manhã como para a parte da tarde. Para cada dia, foram gerados índices DePAN para o período da manhã e para o período da tarde, nas quatro estações. O total calculado é de 8 índices DePAN por nicho.

\subsection{Validação do modelo}

Após a aplicação do método, foi promovida uma validação, considerando que o maior nível de serviço deve também corresponder ao maior número de pessoas e interação entre pessoas. Assim, com a sobreposição das malhas de pessoas e interação entre pessoas com o mapa de valores dos índices DePAN, foi feita uma comparação., verificando-se a fidelidade dos resultados. 


\section{Aplicação do modelo DEPAN: análi- se de resultados}

Os resultados dos dados climáticos coletados serviram de referência para as condições apresentadas pelos dias de análise (Tabela 2).

\subsection{Análises de Resultados da Aplicação do Modelo DePAN nos Subespaços e Ni- chos}

Dentre os subespaços do Parque Vitória Régia, foi realizada a aplicação do modelo DePAN nos subespaços denominados "área de bancos" e "subespaço 19". Os resultados da aplicação desse modelo estão apresentados sinteticamente na Tabela 3, em que são representados os índices obtidos para cada nicho, separados por períodos do dia e estações do ano. As cores na Tabela 3 correspondem às classes DePan anteiormente apresentadas na Tabela 1.

A análise da Tabela 3 permite avaliar a variação no desempenho do nicho entre manhã e tarde, bem como no decorrer das quatro estações. Verificam-se também os momentos, ao longo do dia ou do ano, em que o nicho oferece melhores índices e, assim, proporciona melhores condições de uso.

\subsubsection{Análise de resultados do subespaço área dos bancos}

A comparação entre os períodos da manhã e da tarde para o subespaço inteiro mostra que nos dias de temperaturas baixas a classificação $C$ é dominante. Em compensação, nos dias quentes, não é possível identificar uma única classificação como a mais preponderante. Nesse caso, observa-se apenas que apresentou um índice de serviço de pouco satisfatório a insatisfatório, com classificação D e E.

A avaliação dos nichos separadamente, nas estações de outono e inverno, mostra que a maioria deles ofereceu alto índice de serviço (classe C e B). A comparação entre a classificação do nível de serviço de cada um dos nichos, nos dias frios, no período da manhã e da tarde, mostra que houve alteração em quase todos eles, em função da variação de sol e sombra ao longo do dia e, consequentemente, na temperatura superficial. Os nichos, mesmo não obtendo os valores máximos na avaliação das malhas fixas, conseguiram boa classificação DePAN, por oferecerem níveis altos na avaliação

Tabela 2: Média das variáveis climáticas nos dias avaliados no Parque Vitória Régia

\begin{tabular}{|c|c|c|c|c|c|c|c|c|}
\hline \multirow{3}{*}{$\begin{array}{l}\text { Identificação do espaço público } \\
\text { Parque Vitória Régia }\end{array}$} & \multicolumn{8}{|c|}{ Estações do Ano/ dias dos levantamentos de campo/ identificação dos períodos } \\
\hline & \multicolumn{2}{|c|}{ Outono $4 / 6 / 11$} & \multicolumn{2}{|c|}{ Inverno $3 / 7 / 11$} & \multicolumn{2}{|c|}{ Primavera $11 / 12 / 11$} & \multicolumn{2}{|c|}{ Verão $4 / 3 / 12$} \\
\hline & manhã & tarde & manhã & tarde & manhã & tarde & manhã & tarde \\
\hline Média da temperatura do ar & $15^{\circ} \mathrm{C}$ & $17^{\circ} \mathrm{C}$ & $16^{\circ} \mathrm{C}$ & $18^{\circ} \mathrm{C}$ & $23^{\circ} \mathrm{C}$ & $29^{\circ} \mathrm{C}$ & $29^{\circ} \mathrm{C}$ & $31^{\circ} \mathrm{C}$ \\
\hline Média da umidade relativa & $57 \%$ & $45 \%$ & $50 \%$ & $40 \%$ & $80 \%$ & $62 \%$ & $80 \%$ & $68 \%$ \\
\hline Média da velocidade do vento & $1,3 \mathrm{~m} / \mathrm{s}$ & $1,0 \mathrm{~m} / \mathrm{s}$ & $1,5 \mathrm{~m} / \mathrm{s}$ & $1,2 \mathrm{~m} / \mathrm{s}$ & $0,8 \mathrm{~m} / \mathrm{s}$ & $0,4 \mathrm{~m} / \mathrm{s}$ & $0,5 \mathrm{~m} / \mathrm{s}$ & $0,3 \mathrm{~m} / \mathrm{s}$ \\
\hline
\end{tabular}

Tabela 3: Classificações DePAN para o subespaço "área dos bancos" e de seus nichos

\begin{tabular}{|c|c|c|c|c|c|c|c|c|}
\hline \multirow{4}{*}{$\begin{array}{l}\text { Identificação dos subespaços e } \\
\text { dos nichos }\end{array}$} & \multicolumn{8}{|c|}{ Estações do Ano } \\
\hline & \multicolumn{2}{|c|}{ Outono } & \multicolumn{2}{|c|}{ Inverno } & \multicolumn{2}{|c|}{ Primavera } & \multicolumn{2}{|c|}{ Verão } \\
\hline & \multicolumn{2}{|c|}{ Período do dia } & \multicolumn{2}{|c|}{ Período do dia } & \multicolumn{2}{|c|}{ Período do dia } & \multicolumn{2}{|c|}{ Período do dia } \\
\hline & manhã & tarde & manhã & tarde & manhã & tarde & manhã & tarde \\
\hline Subespaço área dos bancos & $\mathrm{C}$ & $\mathrm{C}$ & $\mathrm{C}$ & $\mathrm{C}$ & $\mathrm{D}$ & $\mathrm{E}$ & $\mathrm{E}$ & $\mathrm{D}$ \\
\hline Nicho 1 & $\mathrm{D}$ & $\mathrm{B}$ & $\mathrm{B}$ & $\mathrm{B}$ & $\mathrm{D}$ & $\mathrm{D}$ & $\mathrm{D}$ & $\mathrm{D}$ \\
\hline Nicho2 & $\mathrm{B}$ & $\mathrm{C}$ & $\mathrm{C}$ & $\mathrm{C}$ & $\mathrm{C}$ & $\mathrm{B}$ & $\mathrm{B}$ & $\mathrm{C}$ \\
\hline Nicho 3 & $\mathrm{D}$ & $\mathrm{C}$ & $\mathrm{D}$ & $\mathrm{C}$ & $\mathrm{D}$ & $\mathrm{E}$ & $\mathrm{D}$ & $\mathrm{D}$ \\
\hline Nicho 4 & $\mathrm{D}$ & $\mathrm{C}$ & $\mathrm{C}$ & $\mathrm{C}$ & $\mathrm{C}$ & $\mathrm{C}$ & $\mathrm{B}$ & $\mathrm{D}$ \\
\hline Nicho 5 & $\mathrm{~B}$ & $\mathrm{C}$ & $\mathrm{B}$ & $\mathrm{D}$ & $\mathrm{C}$ & $\mathrm{C}$ & $\mathrm{B}$ & $\mathrm{C}$ \\
\hline Nicho 6 & $\mathrm{C}$ & $\mathrm{C}$ & $\mathrm{C}$ & $\mathrm{C}$ & $\mathrm{C}$ & $\mathrm{D}$ & $\mathrm{B}$ & $\mathrm{D}$ \\
\hline Nicho 7 & $\mathrm{C}$ & $\mathrm{D}$ & $\mathrm{D}$ & $\mathrm{C}$ & $\mathrm{B}$ & $\mathrm{E}$ & $\mathrm{B}$ & $\mathrm{E}$ \\
\hline Nicho 8 & $\mathrm{~B}$ & $\mathrm{D}$ & $\mathrm{D}$ & $\mathrm{C}$ & $\mathrm{C}$ & $\mathrm{E}$ & $\mathrm{C}$ & $\mathrm{E}$ \\
\hline Subespaço 19 & $\mathrm{C}$ & $\mathrm{C}$ & $\mathrm{C}$ & $\mathrm{C}$ & $\mathrm{B}$ & $\mathrm{B}$ & $\mathrm{B}$ & $\mathrm{B}$ \\
\hline $\begin{array}{l}\text { Quantidade de repetição de uma } \\
\text { classificação ao final do dia }\end{array}$ & $3 \mathrm{~B}$ & $1 \mathrm{~B}$ & $2 \mathrm{~B}$ & $1 \mathrm{~B}$ & $2 \mathrm{~B}$ & $2 \mathrm{~B}$ & $6 \mathrm{~B}$ & $1 \mathrm{~B}$ \\
\hline
\end{tabular}


das malhas dinâmicas (sol/sombra e temperatura superficial). Essa é uma característica do modelo DePAN, que ao incorporar a avaliação do ambiente térmico, permitiu revelar o grau de importância desses atributos na classificação do nível de serviço dos nichos.

A avaliação dos nichos separadamente, nas estações de primavera e verão, mostra que a maior quantidade de índices relacionados às classificações $B$ e $C$ prevalecem no período da manhã, enquanto as classificações D e E tendem a se concentrar no período da tarde.

A classificação geral desse subespaço no dias quentes, se comparada com a classificação de alguns nichos que obtiveram classificações $B$ e $\mathrm{C}$, parece destoante do resultado apresentado pelos nichos individualmente, mas é proveniente da exposição solar da grande área central desse subespaço. A área central é revestida com piso de concreto e está exposto ao sol, apresentando elevados níveis de temperatura superficial. Como a quantidade de células nessa área afetada por esses atributos é normalmente grande em relação ao número de células ocupadas por um nicho, sua influência na média é bastante significativa. No entanto, a avaliação de cada nicho revela que boa parte deles estava em condição de sombra, derivando em melhor classificação. A avaliação desse subespaço mostra que o resultado das classificações dos nichos é decorrente da exposição deles à radiação solar ou a sombra, pois a medida que a temperatura superficial aumentou, apresentou índices fora da faixa de conforto.

\subsubsection{Análise de resultados do subespaço 19}

O subespaço 19 não apresenta nichos caracterizados pelo arranjo espacial dos bancos, nele os nichos são formados pelo próprio agrupamento de pessoas sentadas na grama ou nas raízes das árvores ou pela apropriação individual do espaço. Portanto, o valor apresentado para classificação DePAN é referente ao subespaço inteiro e dispensa os resultados por nichos, uma vez que eles não existem fisicamente.

No caso do subespaço 19, o qual apresenta maior quantidade de arborização e predomínio de solo revestido de grama, identifica-se maior uniformidade e regularidade no seu desempenho ergonômico ambiental. Ao analisar os mapas gerados no SIG para representar as malhas da manhã e da tarde, nas quatro estações do ano, é facilmente identificável a proximidade dos resultados, conferindo a uniformidade.
Nas estações de outono e inverno predomina a classificação $\mathrm{C}$, que representa um bom nível de serviço, tanto de manhã quanto à tarde. Nas estações de primavera e verão prevalece a classificação $B$, que indica um nível de serviço muito bom. Esta classificação é a mesma para manhã e tarde.

\subsubsection{Comparação dos resultados dos subes- paços "área dos bancos" e "19"}

A aplicação do modelo DePAN nestes dois subespaços do Parque Vitória Régia, permite confirmar que o design do espaço influencia a sua ergonomia ambiental. Os elementos de design podem variar, mas mantêm relação com a quantidade e a posição de árvores produzindo efeitos de sol e sombra, bem como com o material empregado no revestimento de piso, com a proporção entre piso de grama e de material construído, dentre outros. Isto fica claro ao serem confrontadas as classificações recebidas por cada subespaço nas quatro estações do ano.

A avaliação das classes atribuídas pelo modelo DePAN mostra, ainda, que as diferenças de resultados entre os subespaços "área dos bancos" e "19" são maiores nos dias quentes (primavera e verão), ao passo que nos dias frios (outono e inverno) há maior uniformidade na classificação. Isto ocorre porque nos dias frios a área de sombra no subespaço área dos bancos foi maior do que nos dias quentes e, sob condições de sombra, o comportamento térmico dos materiais de revestimento de piso foi semelhante.

Entretanto, em condições de exposição ao sol, a temperatura superficial do concreto se eleva rapidamente e se estabelece com uma diferença muito superior a da grama. Assim, é classificado em outra faixa de temperatura e, na maioria das vezes, não atende aos níveis de serviço considerados bons para o desempenho ergonômico ambiental. Esta condição foi especialmente identificada no subespaço área dos bancos, para o qual, nos dias frios, observouse a uniformidade dos valores e, nos dias quentes, foram registradas grandes diferenças de temperatura superficial entre o concreto e a grama.

Verifica-se também que apesar do subespaço 19 não obter pontuação nos itens bancos e arranjo dos bancos, pela escassez desses atributos, ele apresenta bom nível de serviço, por compensar nos demais atributos. O subespaço 19 apresenta temperaturas superficiais mais baixas nos dias 
quentes do que foi registrado no outro subespaço, reafirmando as vantagens da vegetação para efeito térmico, tanto do piso de grama, como das árvores. Ressalta-se ainda que, apesar da importância ergonômica dos bancos e sua configuração em si, nem sempre esse mobiliário urbano é indispensável para a permanência e atratividade de pessoas em espaços públicos abertos, pois pode ser compensado pela presença de outros elementos (no caso a sombra das árvores sobre vasto espaço gramado), conforme demonstra o modelo DePAN.

A compensação da ausência de bancos é demonstrada pela forma de uso desse subespaço por pessoas de todas as faixas etárias. Os jovens utilizam o espaço para piquenique e prática de esportes. Os adultos, as crianças e os idosos fazem piqueniques, brincam e descansam. O sentar ou deitar é feito sobre toalhas e, assim, as pessoas, independente da faixa etária, passam muito tempo (em média 3 horas). O subespaço revela que as pessoas que o escolhem já vão com a pré-disposição de permanecer no lugar e por isso levam consigo o que precisam, seja a toalha para sentar ou deitar, os alimentos e os equipamentos usados para brincar ou praticar esportes. Este subespaço, assim como os subespaços adjacentes, é ocupado por pessoas que o escolheram pela possibilidade de desfrutar da sombra, associado à ausência de mobiliários urbanos, o que lhes permitem uma forma mais livre de apropriação do espaço.

\subsection{Validação do Modelo DePAN}

Para apresentar a validação do modelo DePAN no Parque Vitória Régia, foi selecionado o subespaço 19 (Figuras 6 e 7), que possui características de design e de ergonomia específicas em relação ao subespaço área dos bancos e, ao mesmo tempo, é significativa para o parque.

Figura 6: Malhas de validação com os níveis de serviço DePAN para o período de outono (frio) na parte da manhã

Malha Vitória_19 Outono (04/06/2011) manhã

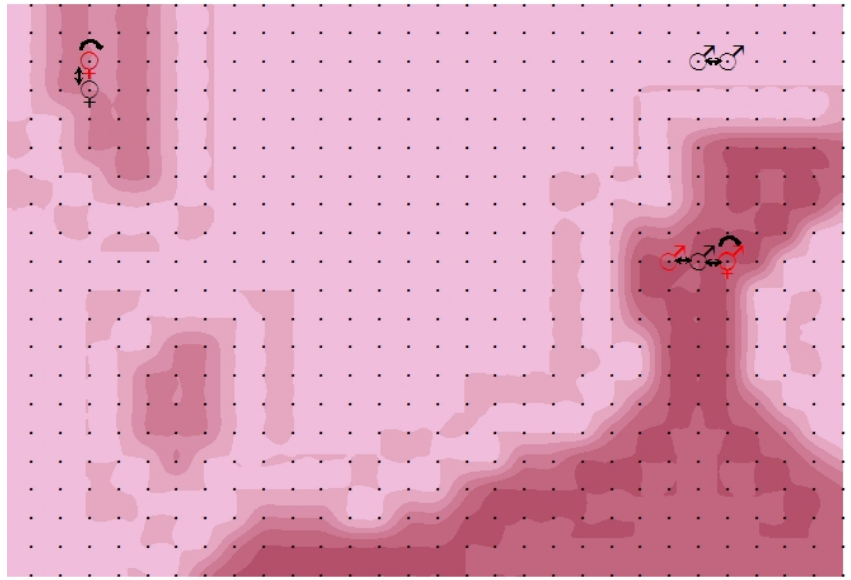

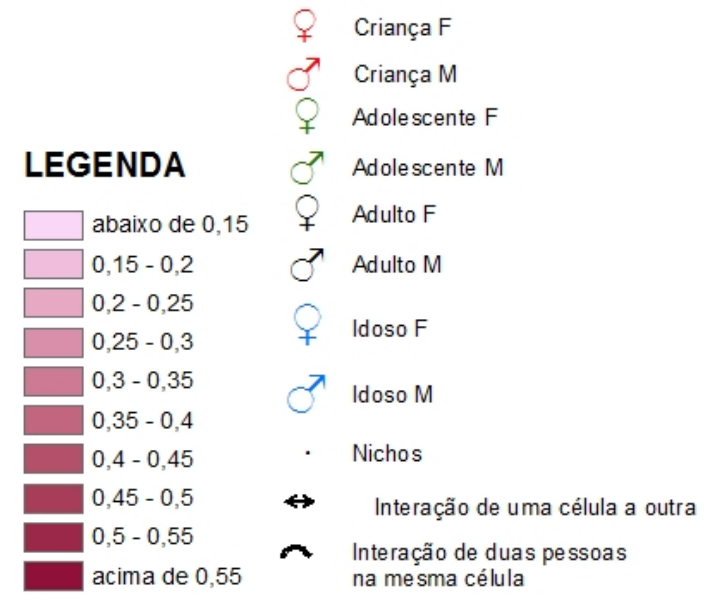

Figura 7: Malhas de validação com os níveis de serviço DePAN para o período de primavera (quente) na parte da tarde

Malha Vitória 19 Primavera (11/12/2011) tarde

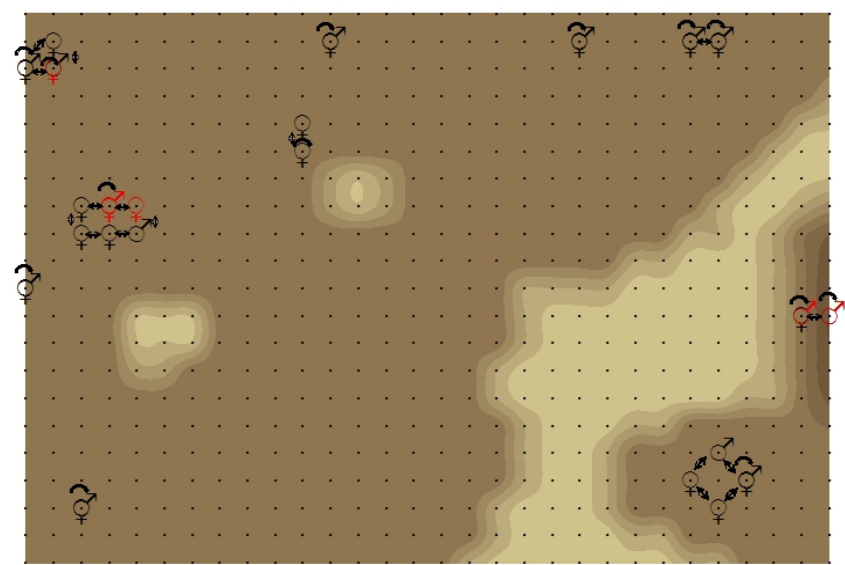

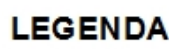

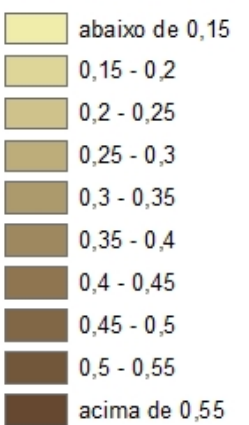

Criança F

Criança M

Adolescente $\mathrm{F}$

Adolescente M

Adulto $\mathrm{F}$

Adulto $\mathrm{M}$

Idoso $\mathrm{F}$

Idoso M

Nichos

$\leftrightarrow \quad$ Interação de uma célula a outra

- Interação de duas pessoas na mesma célula 
$\mathrm{Na}$ Figura 6 observa-se que a forma de organização das pessoas em dupla ou em grupos é que configura o arranjo espacial do nicho. Na distribuição das pessoas registrada para a manhã de outono, pode ser notado que as regiões com pontuação DePAN mais altas tenderam a ser aquelas onde ocorreu maior número de ocupantes e interação. Ao todo são nove pessoas, de todas as faixas etárias, ocupando este subespaço.

Quando verificada a Figura 7, para o período da tarde na primavera, constatou-se que os espaços com níveis de serviço mais altos foram os mais ocupados por duplas ou grupos de pessoas. Ao todo foram trinta e seis pessoas, de todas as faixas etárias, ocupando este subespaço. Regiões com médias DePAN abaixo de 0,25 encontraram-se desocupadas.

O subespaço 19 apresentou classes DePAN diferentes nas estações do ano outono e primavera (Figuras 6 e 7). No outono, manhã, recebeu classificação $C$ e na primavera, tarde, apresentou classificação B. A comparação direta entre manhã fria de outono com a tarde quente de primavera mostra uma significativa aderência entre a classe DePAN e a ocupação/interação de pessoas.

\section{Conclusões}

O modelo DePAN permitiu verificar que as características espaciais, ergonômicas e a qualidade térmica gerada pelo design dos espaços abertos de convívio interferem na sua usabilidade, contribuindo para gerar os nichos de permanência e atratividade. O modelo permite a sobreposição das malhas fixas e dinâmicas, e possibilita a classificação do nível de serviço oferecido pelo nicho. A identificação dos atributos favoráveis e dos desfavoráveis para cada estação do ano ou período do dia resultou na classificação dos nichos de A a E.

Os nichos apresentam desempenhos diferentes, mesmo estando implantados em um mesmo subespaço, conforme se verificou na área dos bancos. Este resultado comprova que o ambiente térmico, um dos atributos do modelo, sofre interferência do design do nicho. Essa interferência é dependente das características físico-arquiteturais e ambientais do nicho. Isto é, a porção de sombra que atinge o nicho ou a porção de exposição ao sol, associada às características dos materiais de revestimento do piso e bancos, resultam em condições que afetam o desempenho do nicho de acordo com a estação do ano.
Entre os atributos avaliados constatou-se que aqueles relacionados aos bancos são importantes, mas não são imprescindíveis para promover a usabilidade do espaço.

As malhas de validação do modelo serviram para mostrar as formas de uso do espaço, verificar se ocorrem as interações sociais e observar as preferências por alguns nichos, de acordo com as atividades desenvolvidas pelos usuários. Assim, o modelo DePAN revelou-se uma ferramenta adequada para avaliação de espaços públicos abertos, uma vez que a classificação pelo nível de serviço possibilita identificar os atributos mais significativos para seu bom desempenho. Além dos atributos que foram selecionados para avaliação, outros aspectos podem ser introduzidos no modelo, desde que seja realizada uma normalização de valores entre 0 e 1.

\section{Referências Bibliográficas}

ABNT - ASSOCIAÇÃO BRASILEIRA DE NORMAS TÉCNICAS. NBR - 15220-2: Desempenho Térmico de Edificações. Parte 2: Métodos de cálculo da transmitância térmica, da capacidade térmica, do atraso térmico e do fator de calor solar de elementos e componentes de edificações. Rio de Janeiro, 2005.

ALVES, Silvana Ap. Design para a Permanência e Atratividade em Nichos de espaços abertos de convívio: DePAN. 2012. Tese (Doutorado em Design) Faculdade de Arquitetura, Artes e Comunicação, Universidade Estadual Paulista, Bauru, 2012.

BINS ELY, Vera Helena Moro. Avaliação de fatores determinantes no posicionamento de usuários em abrigos de ônibus a partir do Método Grade de Atributos. Tese (Doutorado). Universidade Federal de Santa Catarina, Florianópolis-SC, 1997.

BRUSE, Michael. Simulating human thermal comfort and resulting usage patterns of urban open spaces with a Multi-Agent System. In: Wittkopf, St. and Tan, B. K. (eds.): Proceedings of the 24th INTERNATIONAL CONFERENCE ON PASSIVE AND LOW ENERGY ARCHITECTURE - PLEA, p.699-706 2007. Anais... 2007.

HALL, Edward T. A dimensão oculta. $2^{a}$ edição. Rio de Janeiro: Francisco Alves, 1977.

KATZSCHNER, Lutz. A methodology for bioclimatic microscale mapping of open 
spaces. 2003. Disponível no site: http://nargeo. geo.uni.lodz.pl/ icuc5/text/P_1_1.pdf. Acesso em fevereiro de 2012.

LAMBERTS, Roberto; XAVIER, Antonio Augusto de $P$. Conforto térmico e stress térmico. Laboratório de Eficiência Energética em Edificações. Universidade Federal de Santa Catarina Centro Tecnológico. Departamento de Engenharia Civil. Florianópolis, 2002.

NIKOLOPOULOU, Marialena; STEEMERS, Koen. Thermal comfort and psychological adaptation as a guide for designing urban spaces. Energy and Building $\mathrm{n}^{\circ} 35,2003, \mathrm{p}$. 95-101, 2003.

PANERO,Julius e ZELNIK, Martin. Las dimensiones humanas em los espacios interiores: estándares antropométricos. México, Ed. Gustavo Gilli, 1989.

SILVA, José Carlos Plácido da; J. C. P.; FRANCO; SPINOSA, R. M. Interface antropométrica digital: Público infantil; da pré-escola ao ensino fundamental. LEI-DDI-PPGDI-FAAC, Universidade Estadual Paulista, Bauru, 2008b, CD-ROM.

SOMMER, Robert. Espaço pessoal. São Paulo, Edusp, Editora da Universidade de São Paulo, 1973. 